REGARDS

SUR LECONOMIE ALLEMANDE

BULLETIN ECONOMIQUE DU CIRAC
Regards sur l'économie allemande

Bulletin économique du CIRAC

$92 \mid 2009$

Varia

\title{
Un viatique pour Lisbonne
}

René Lasserre

\section{OpenEdition}

Journals

Édition électronique

URL : http://journals.openedition.org/rea/3731

DOI : 10.4000/rea.3731

ISBN : 978-2-8218-0880-5

ISSN : 1965-0787

Éditeur

CIRAC

Édition imprimée

Date de publication : 1 juillet 2009

Pagination : 1-2

ISSN : 1156-8992

Référence électronique

René Lasserre, « Un viatique pour Lisbonne », Regards sur l'économie allemande [En ligne], 92 I juillet 2009, mis en ligne le 28 août 2009, consulté le 22 septembre 2020. URL : http://

journals.openedition.org/rea/3731; DOI : https://doi.org/10.4000/rea.3731

(c) CIRAC 


\section{Un viatique pour Lisbonne}

L'Allemagne est doublement en expectative : face à la crise, l'économie allemande retient son souffle, aux aguets du moindre signe qui pourrait annoncer la reprise. Et à l'approche de l'échéance électorale du 27 septembre, les forces politiques jouent la course d'attente, remontant lentement vers le haut de la piste et s'observant avant d'aborder le dernier virage...

Les juges du Tribunal constitutionnel n'auraient $\mathrm{pu}$ choisir meilleur moment pour capter l'attention des Européens en rendant le 30 juin leur jugement sur le Traité de Lisbonne, d'autant que les 74 pages remises à cette occasion, bien qu'un peu indigestes, méritent qu'on s'y arrête. Il est vrai que le verdict des juges était attendu, et redouté. Alors même que le blocage irlandais était en passe d'être surmonté, les juges de Karlsruhe n'allaient-ils pas, à leur tour, apposer quelques cadenas sur le parcours d'obstacles qui mène à la ratification du Traité de Lisbonne et à la réforme effective des institutions européennes ?

Le jugement a été accueilli avec soulagement en Allemagne et dans toute l'Europe : le Traité de Lisbonne est bel et bien compatible avec la Loi fondamentale et la République fédérale pourra le ratifier... moyennant quelques aménagements politiques internes concernant les droits de regard du parlement en matière de transferts de souveraineté.

Que le traité soit jugé conforme aux principes de la Constitution ne constitue pas à proprement parler une surprise, car la Cour constitutionnelle s'est toujours montrée favorable à l'intégration européenne. Ce qui est plus original et pour tout dire inédit, ce sont les raisons positives qu'avance le Tribunal pour justifier la compatibilité du Traité avec les principes constitutionnels fondamentaux de la République fédérale. Il s'agit d'une démonstration magistrale qui, à notre sens, fera enfin avancer la réflexion politique sur la nature de l'Union et sur le sens de la construction européenne. En effet, au-delà des catégories abstraites ou formules imagées dont rivalisent les hommes politiques pour " penser " l'architecture ou la "gravitation " de l'Europe, les juges de Karlsruhe en explicitent clairement la façon et la raison d'être. L'UE est une " union d'Etats associés ", lesquels ont décidé de déléguer à l'Union par voie de traité une partie de leur souveraineté tout en cherchant à préserver les éléments qui fondent leur identité nationale. Il en découle que la délégation de souveraineté à l'Union relève tout entière de la libre disposition des Etats et qu'elle émane ainsi de la seule légitimité démocratique de leurs citoyens. Elle ne peut donc être étendue qu'avec l'assentiment formel de ceux-ci ou des organes qui les représentent dans le cadre constitutionnel qui est le leur, sans que par ailleurs, dans le champ national où elle s'exprime, leur identité souveraine doive s'en trouver aliénée. Et sur ce point, le TCF énumère une série de domaines de souveraineté pour ainsi dire "irréfragables ", véritable décalogue qui devrait enfin contribuer à donner corps à la définition européenne commune d'un noyau dur de la subsidiarité.

Dans le cas de l'Allemagne, comme le montre l'analyse très minutieuse du jugement que nous livre dans le présent numéro l'étude du Professeur Müller-Graff, l'intégration européenne est inscrite dans la Loi fondamentale au rang des priorités constitutionnelles, tout autant que le sont un certain nombre de principes d'organisation constitutionnelle 
intangibles tels que l'Etat de droit, l'Etat social, le fédéralisme. Il en découle que non seulement les citoyens doivent être associés à la politique européenne par l'intermédiaire du Bundestag, mais aussi les Länder par celle du Bundesrat (art. $23 \mathrm{LF}$ ). La constitutionnalité de l'adhésion au traité de Lisbonne ne pose donc en elle-même aucun problème dans la mesure où elle ne remet en cause aucun de ces principes. La question commence néanmoins à se poser dès lors que le traité prévoit, lorsqu'il aura été ratifié, de nouvelles règles de majorité et de nouveaux processus de décision du Conseil européen. Lesquels permettront que le traité puisse être modifié et que de nouveaux transferts de compétence pourront être consentis hors ratification par des procédures ordinaires et interchangeables selon les cas de figure.

C'est notamment sur ce point que les juges ont concentré leur attention en analysant les modalités d'exercice des délégations de compétences par le législateur national et qu'ils ont émis de fermes exigences assorties d'une réserve formelle en constitutionnalité. Ce second volet du jugement suscite davantage de circonspection, tant au plan des exigences politiques qu'il implique qu'au plan des principes. Concrètement, ce qui est en cause, ce sont les conditions dans lesquelles la Loi (non encore publiée) sur l'extension et le renforcement des pouvoirs consultatifs du parlement en matière d'affaires européennes prévoit que le Bundestag et le Bundesrat devront être formellement consultés dans toutes les formes assouplies de prise de décision. Les pouvoirs provisoirement reconnus aux deux assemblées sont à cet égard jugés insuffisants et doivent être réaménagés au regard de la responsabilité constitutionnelle qui leur incombe en matière de transferts de souveraineté.

Outre qu'il est difficile de prévoir dans quel délai et selon quelles formes ce réaménagement pourra intervenir, se pose la question des conditions dans lesquelles il pourra s'exercer à terme pour rester compatible avec l'efficacité du processus de décision communautaire. Cette question ne se pose cependant pas que pour l'Allemagne, mais pour tous les pays qui devront d'ici là trouver un nouvel équilibre entre efficacité accrue et légitimité requise du processus d'intégration. Enfin, la question du contrôle "d'intégration abusive " ou "débordante " que revendique le TCF dans son espace constitutionnel pose un problème de fond : est-il envisageable que chaque Etat laisse le soin à sa juridiction nationale de déterminer si un acte juridique européen s'applique ou non sur son territoire, ce qui serait la négation même de la primauté du droit européen et du principe d’intégration ? Ce qui revient à poser la question incontournable, trop longtemps négligée par les politiques, de l'existence d'une juridiction européenne ou de l'extension des prérogatives de la Cour européenne de Justice.

Les juges de Karlsruhe font toujours dans la dentelle, en ce sens qu'ils ne laissent rien au hasard. On aurait cependant tort de voir dans l'évaluation prospective exigeante du TCF une dérive souverainiste ou une volonté de verrouiller le processus dynamique de l'intégration. Il cherche plutôt à établir, à partir d'un expérience allemande qui a fait ses preuves, un ensemble de critères à partir desquels doit pouvoir s'affirmer à l'échelle européenne une définition et un contrôle effectifs de la subsidiarité sur la base desquels pourra s'établir un équilibre durable et praticable entre intégration européenne et identité nationale. 